\title{
A literatura como SUPLEMENTO dA HiStóRia EM MEMÓRIAS SILENCIADAS SOBRE A NAÇÃO
}

SILVA, Fabiana Carneiro da. Ominíbú - maternidade negra em Um defeito de cor. Salvador: EDUFBA, 2019. 228p.

\section{U}

m projeto de nação só é legítimo se reconhece todos os elementos que historicamente constituem os elos que formam aquilo que se pode compreender como povo. Essa é uma premissa ainda distante da realidade - especialmente no caso brasileiro -, onde a democracia é solapada por projetos obscurantistas, engendrados por falsos messias e apoiados por expressiva massa obnubilada por fake news, engenhosamente a serviço de quem sempre esteve em posição de mando.

Por isso, discutir elementos de representação da nacionalidade a partir do tensionamento entre enunciados diversos torna-se exercício estratégico para a reescrita das relações sociais, na busca por reparação de justiça a sujeitos historicamente invisibilizados. Esse é o desafio a que se impôs a pesquisadora Fabiana Carneiro da Silva em seu estudo sobre o romance Um defeito de cor, de Ana Maria Gonçalves.

O livro inicia com a enunciação do seu lugar de escrita: pede a benção de Omolu e licença para apresentar sua pesquisa acadêmica, reconhecendo, assim como Ana Maria Gonçalves, que os caminhos percorridos por uma mulher negra de pele clara são distintos nos níveis de opressão dos caminhos reservados às mulheres negras de pele preta. O reconhecimento do lugar de fala é uma demonstração lúcida do complexo panorama do racismo estrutural brasileiro, mas também se 
apresenta como discurso engajado criticamente na luta antirracista.

A hipótese/pergunta norteadora da pesquisa foi elaborada a partir do título do romance estudado: "defeito de cor” é uma alusão à lei colonial "que requeria um termo de dispensa, o qual as pessoas 'de cor', isto é, negros e 'mulatos', necessitavam assinar no momento da investidura em um cargo público ou eclesiástico” (p. 27). Com isso, "pessoas de cor" que se destacassem em um ofício precisavam pedir desculpas por trazer no corpo as evidências de sua ascendência africana, o que seria seu "defeito de cor”. A primeira referência utilizada pela autora, logo na introdução, é do poeta, jornalista e advogado abolicionista Luiz Gama, o filho roubado a quem se dirige a longa narrativa de Um defeito de cor, quando ele afirma:

Em nós, até a cor é um defeito, um vício imperdoável de origem, o estigma de um crime; e vão ao ponto de esquecer que esta cor é a origem da riqueza de milhares de salteadores, que nos insultam; que esta cor convencional da escravidão, como supõem os especuladores, à semelhança da terra, ao través da escura superfície, encerra vulcões, onde arde $\mathrm{o}$ fogo sagrado da liberdade (p. 27).
O enunciado de Luiz Gama, datado de 1880 e vergonhosamente contemporâneo, aponta para o questionamento basilar da estrutura sobre a qual se montam as sociedades escravistas: afinal, qual é e de quem é o crime? $O$ defeito perverso que repercute, ainda hoje, enquanto racismo e desigualdade, só pode ser compreendido se deslocado do cinismo colonial para a compreensão e assunção das consequências sociais da escravidão. Daí a importância de compreender as múltiplas estratégias do racismo e analisar seus efeitos em perspectiva interseccional, já que os marcadores de gênero, classe e raça se atravessam como consequência de práticas de opressão, minuciosamente analisadas por Fabiana Silva em sua leitura do romance de Ana Maria Gonçalves.

A autora divide suas reflexões em três capítulos, além da introdução e das considerações finais. A autora dedica o primeiro capítulo a apresentar a discussão, cara aos estudos literários, sobre a relação entre literatura e história a partir do tensionamento presente em Um defeito de cor. Este, além de iniciar com o mote tradicional de romances históricos (documentos 
antigos encontrados, um diário perdido, uma carta esquecida...), opera como suplemento da história.

Fabiana Silva inicia a discussão sobre o caráter dessa suplementaridade pela análise da ficcionalização que a própria Ana Maria Gonçalves faz de si, quando se coloca como personagem da narrativa, apresentando-se como tal na introdução ao romance, chamada "Serendipidades". Considerando que o enredo tem como um dos seus momentos cruciais a narração dos episódios relativos à Revolta dos Malês e a importância desse evento histórico para a construção da protagonista Kehinde / Luíza Mahin, a autora de Ominíbú apresenta o modo como, em Um defeito de cor, o estudo de João José Reis sobre a referida rebelião deixa de ser apenas uma referência de consulta (como é na bibliografia apensa ao romance) e passa a ser, em determinados trechos da ficção, mais uma voz na composição polifônica que se apresenta como memória dos movimentos insurrecionais impetrados pelas pessoas escravizadas.

A percepção da intertextualidade entre Rebelião escrava no Brasil $^{1} \mathrm{e}$

1 Ana Maria Gonçalves indica como referência bibliográfica as seguintes obras
Um defeito de cor aponta para um movimento de rasura a que a literatura submete o texto historiográfico, pois o texto literário pode construir outros sujeitos representativos e refundar mitos, por ter compromissos ancorados em outros paradigmas. Assim, se o estudo baseado em documentos e evidências históricas não pode afirmar a participação expressiva de mulheres nas rebeliões escravas, a literatura o faz, e traz para a frente da cena a voz de Luíza Mahin (cujo nome ficcional africano é Kehinde), a mãe mencionada por Luiz Gama em uma carta autobiográfica. Mulher símbolo da resistência e da maternidade negra, Luíza Mahin é silenciada nas narrativas históricas, mas se torna a narradora do romance de Ana Maria Gonçalves, concebido como uma longuíssima carta a seu

de João José Reis: Rebelião escrava no Brasil: a história do levante dos Malês em 1835 (em sua primeira edição, mais condensada, publicada em 1986 pela Editora Brasiliense); A morte é uma festa - ritos fúnebres e revolta popular no Brasil do século XIX, São Paulo: Companhia das Letras, 1991; e (com Eduardo Silva), Negociação e conflito, São Paulo: Companhia das Letras, 1989. Fabiana Silva usa a $3^{\text {a }}$ ed. de Rebelião escrava no Brasil: a história do levante dos Malês em 1835, publicada em 2003 também pela Companhia das Letras. 
filho desaparecido, que tendo nascido liberto fora vendido como escravo pelo próprio pai branco.

Como aponta Silva, Um defeito de cor narra uma outra "história", decerto ausente na pesquisa historiográfica: a de uma mulher africana que veio para o Brasil, ainda criança, na condição de escravizada, mas que superou esta condição, tanto por sua resiliência, como por ter contado, ao longo de sua trajetória, com o apoio de uma rede solidária criada entre negros escravizados e libertos, mas também de algumas pessoas brancas engajadas na causa abolicionista.

Por este aspecto, Gonçalves redimensiona ficcionalmente os fatos e constrói novas possibilidades de leitura da história. Para a compreensão desse movimento, Silva recorre a referências da Teoria da Literatura, que revisam conceitos caros ao marxismo histórico de Lukács, passando pelo estruturalismo Bakthiniano até chegar ao conceito de oralitura, na perspectiva apresentada por Leda Martins, e a historiadores que discutem a intersecção entre literatura e história, como Hayden White, Michel de Certeau e Roger Chartier.
Ainda no primeiro capítulo, Silva descobre uma narrativa da história que se contrapõe aos documentos, mas menciona também como o desejo de uma referencialidade historiográfica marcada pela presença de textos de João Reis e de outros historiadores molda uma dicção que Fabiana Silva considera impostada do romance, uma quase artificialidade da memória que, sendo narrada por uma mulher idosa, doente e quase cega, se apresenta linear e minuciosa ao relatar fatos ocorridos décadas antes. Ao explorar esse aspecto, a autora demonstra como a narrativa de Um defeito de cor, por um lado, beira o limite do pacto de confiabilidade entre leitor e obra, mas, por outro lado, ressalta que há um acordo adicional implícito: apresentar, através de Kehinde, um panorama do longo período histórico que abarcou o escravismo no Brasil, as relações de "negociação e conflito", as circunstâncias de retorno à África e estabelecimento dos retornados em seus países de origem.

A trajetória de Kehinde é atravessada pela maternidade e cada gestação marca as mudanças no corpo e na personalidade da protagonista, bem como reflete sua condição social 
expressa nas relações interpessoais, religiosas e políticas. A maternidade negra torna-se elemento central nos segundo e terceiro capítulos de Ominíbú.

No segundo capítulo, Fabiana Silva segue o caminho traçado por outras mulheres e monta um bordado teórico-crítico, baseado em estudos relevantes sobre escrita de si e subjetividades negras, para analisar a relação entre a carta ficcional escrita por Luíza Mahin e cartas reais, de mulheres negras escravizadas, reveladas pela pesquisa de Maria Cristina Cortez Wissenbach. ${ }^{2}$ Através dessa fonte histórica, Silva percebe características como resiliência e determinação, bem como é possível vislumbrar nelas ações/movimentos de busca da liberdade, da restituição da família, da restauração da dignidade roubada pela escravidão.

Da leitura comparada entre a carta de Luiz Gama - documento histórico - e a carta ficcional de Luíza

2 Maria Cristina Cortez Wissenbach, “Teodora Dias da Cunha: construindo um lugar para si no mundo da escrita e da escravidão” in Giovanna Xavier; Juliana Barreto Farias e Flávio dos Santos Gomes (orgs.), Mulheres negras no Brasil escravista e do pós-emancipação (São Paulo: Selo Negro Edições, 2012), pp. 227-242
Mahin / Kehinde, Fabiana Silva desvenda o método de composição do romance Um defeito de cor, escrito a partir da justaposição de gêneros em que se entrelaçam escrita de si, relato memorialístico e romance histórico. O reconhecimento dessas camadas discursivas é relevante, pois permite compreender como a figura de Luíza Mahin assumiu o estatuto de mito e ícone para as mulheres negras, que legitimam a sua presença histórica através de textos literários, saraus, peças teatrais, músicas e homenagens.

Ao propor uma leitura cruzada entre a presença histórica legitimada pelos documentos e o mito em torno de Luíza Mahin, Silva assinala, para além da leitura de Um defeito de cor, que

as comunidades negras no Brasil precisam lidar com o fato de que sua relação com a palavra escrita foi sistematicamente obstruída e, como gesto correlato a essa tentativa de interdição, os poucos documentos escritos que registram as experiências individuais e percursos sociais dos indivíduos constituintes desses grupos, ao longo dos séculos XVIII e XIX foram rasurados, quando não, destruídos. Se vistos a partir desse contexto, os episódios que circunscrevem o nome de Luíza Mahin visam atribuir autenticidade à 
trajetória dessa mulher e criam um sistema de reconhecimento e reprodução social à revelia do discurso historiográfico e, nesse sentido, em tensão com o enunciado que se vincula ao campo concebido como produtor científico de conhecimento (p. 115).

Embora destaque a necessidade de reconhecimento de sujeitos como Luíza Mahin para a história, o trecho supracitado aponta para uma análise que vai na contramão do próprio romance de Ana Maria Gonçalves, já que, ao afirmar que há poucos documentos sobre experiências individuais negras, desconsidera que, nas obras de referência apresentadas ao final do romance, há estudos importantes sobre diversos aspectos da experiência e mesmo subjetividade de pessoas negras do período abrangido pelo relato de Luíza. Na bibliografia apresentada em Um defeito de cor há, inclusive, a menção a "fontes primárias - documentos, anais, revistas e jornais - dos acervos: Arquivo Histórico Municipal de Salvador; Arquivo Público do Estado da Bahia; Instituto Histórico e Geográfico da Bahia”. ${ }^{3}$

3 Gonçalves, Um defeito de cor, p. 951.
No livro Rebelião escrava no Brasil, tomado como objeto de análise em Ominíbú, consta, além da pesquisa apresentada pelo autor, uma vasta lista de obras de referência, incluindo documentos históricos basilares para um conjunto de pesquisas que vêm sendo desenvolvidas contemporaneamente sobre o tema. A afirmação de Fabiana Silva acaba por evidenciar que, mais do que ausência de fontes, talvez haja poucas condições de acesso, pouco fomento à pesquisa e uma restrição das discussões aos círculos de especialistas no tema.

No entendimento de Fabiana Silva, o modo como a personagem Luíza Mahin é construída no romance aponta para a compreensão de como a literatura suplementa o discurso histórico, no sentido derridiano de preenchimento de uma lacuna no discurso. A autora considera que, se o acesso à escrita esteve interditado, a ficção recorre aos rastros e memórias salvaguardados pela oralidade, nos provérbios, contos, conselhos e mitos, na compreensão de que a oralitura é um procedimento possível, que une corpo e voz, para a elaboração de discursos. Segundo Silva, esse é o grande desafio de 
Um defeito de cor que, como literatura, dialoga com repertórios da oralidade, da memória e da carta de Luiz Gama - documento histórico para dar voz à mãe negra Kehinde. Contudo, a autora não se debruça sobre a análise de como esses elementos discursivos que foram se aderindo ao mito em torno de Luíza Mahin estão ligados às estratégias do Movimento Negro para a necessária representatividade de personagens negras invisibilizadas pela história.

A ênfase da discussão refere-se à construção dessa personagem que é mãe, africana, que atravessa a experiência da escravidão e da conquista da liberdade, a partir de seu próprio protagonismo e do apoio de redes de solidariedade. Ela enfrenta a morte do primeiro filho e o sequestro do segundo, exerce a religião de suas ancestrais, participa de modo muito ativo de movimentos de libertação, adquire prestígio no Brasil e na África, após seu retorno, tem mais dois filhos e, assim, constrói para si uma trajetória ímpar.

Da discussão sobre a criação ficcional de Luíza Mahin e de sua relação com as representações de mulheres negras na literatura surge o terceiro e último capítulo do livro. Este talvez seja o capítulo mais maduro do livro de Silva, quando a autora imprime à crítica literária o tom de sua própria voz com mais veemência, marcando o seu lugar de mulher negra pesquisadora, mãe e filha que se posiciona diante do racismo contemporâneo. A discussão se volta para a denúncia da "violência intrínseca à construção ideológica do Brasil como nação" (p. 142) e do modo como a maternidade de mulheres negras, na literatura brasileira, esteve representada a partir do estereótipo da "mãe preta”.

Ao problematizar essa representação, a autora critica a romantização das relações escravistas brasileiras em obras canônicas como Casa Grande \& Senzala, de Gilberto Freyre, e o modo como a figura da "mãe preta” foi apresentada, nessa e outras obras, como atenuante dos conflitos inerentes à relação entre mulheres escravizadas e senhores escravistas. A “mãe preta” se apresenta como criatura dócil, capaz de zelar pelos filhos dos senhores com mais dedicação e ternura do que de seus próprios filhos. Silva aponta como a personagem foi representada 
por autores como José Lins do Rego, Carlos Drummond de Andrade, Manuel Bandeira e José Américo de Almeida, entre outros, mostrando que, mesmo no projeto modernista de elaboração da identidade nacional, os negros estiveram relegados a lugares fixos de subalternidade, em particular a mulher negra.

Seguindo o método adotado nos capítulos anteriores, a autora coloca em contraponto texto literário e referência histórica e explica como a literatura se apresenta como testemunha de valores sociais. Para compreender a construção da figura da "mãe preta", ela encontra, em anúncios de aluguel de ama de leite nos jornais, o retrato da mercantilização do leite materno durante a escravidão e mesmo depois da abolição. Ao contrário do que se apresenta na idealização literária, a história mostra como a vida dessas mulheres era marcada pela violência e pela precariedade, o que, para a autora, se confirma ainda hoje nas condições das trabalhadoras domésticas. A presença das “mães pretas” na literatura marca uma ausência que, paradoxalmente, também é reveladora da sujeição e da dignidade das pessoas escravizadas: onde estão seus filhos?
A pesquisa aponta para o abandono e o esgarçamento dos laços familiares devido à sonegação do direito à maternidade da mulher escravizada.

A autora apresenta outra face da interdição à maternidade, a partir da representação da mulata. Ao contrário da "mãe preta”, que alimenta em falsa harmonia as relações entre senhores e escravizados, a mulata é a representação do corpo hiperssexualizado, mas estéril. A própria etimologia da palavra remete à animalização desse corpo que serve ao trabalho do sexo, mas que se mostra inválido para a perpetuação da família, como se percebe em personagens canônicas de Jorge Amado, como Rita Baiana e Gabriela, entre outras. Embora não se debruce sobre o conceito de “disrupção" anunciado no título do capítulo, a autora delineia os parâmetros do projeto literário de construção da nacionalidade, do romantismo ao modernismo, e aponta para a necessidade de reescrever as narrativas que fixam os sujeitos negros nos lugares de subalternidade ou de vilania.

Diante da evidente baixa representatividade de mulheres negras na literatura brasileira, torna-se, para a 
autora, fundamental a visibilidade de outros textos, comprometidos com a reparação das injustiças legadas ao povo negro e que consigam desvelar a complexidade das relações sociais que impactam a vida dessas mulheres. Este é o exercício realizado por autoras e autores engajadas/ os na produção de outras possibilidades discursivas, tanto na literatura quanto na crítica literária, de modo a inscrever na história outros signos fundantes, como Um defeito de cor faz ao representar Luíza Mahin.

Na discussão sobre a maternidade de Luíza Mahin, Silva faz o percurso de reconhecimento de pesquisas anteriores, como a de Vânia Vasconcelos, sobre a maternidade, gênero e raça em escritoras afro-brasileiras, especialmente na análise da representação de Kehinde como contraponto aos estereótipos do cânone. ${ }^{4}$ "Ao caracterizar-se a si mesma, na narração ficcional”, escreve Silva, "Kehinde descreve uma mulher de pele preta que, dentre outros fatores, é detentora da

4 Vânia Vasconcelos, No colo das Iabás: maternidade, raça e gênero em escritoras afro-brasileiras, Fortaleza: Edições Demócrito Rocha, 2015. capacidade de concepção no ato de dar à luz a quatro filhos: Banjokô, Omotunde (Luiz), João e Maria Clara” (p. 168).

Compreender a complexidade da maternidade negra a partir dessa personagem é tarefa que perpassa a leitura das várias travessias que a narrativa apresenta: da África para o Brasil, do Brasil para a África e da África para o Brasil novamente. À medida em que a narrativa avança, evidencia-se a complexidade dessa protagonista que, distante de se enquadrar em estereótipos, assume, nesse relato que Luíza Mahin denomina como "pedido de desculpas" ao filho perdido, suas contradições, conquistas e aquilo que ela define como culpas. Fabiana Silva aponta para esse sentimento de culpa como um dos elementos da maternidade de Kehinde, especialmente no que diz respeito ao filho perdido, fruto da união amorosa com o português Alberto, quando ela e seu primeiro filho já estavam libertos.

Segundo a autora, "esse personagem, desde a ótica de Kehinde, vai sendo gradativamente caracterizado ao longo da narrativa como um homem de fraco caráter” (p. 176). Essa fraqueza, que se comprova na 
incapacidade de ele assumir o relacionamento com uma mulher negra, acentua-se com o casamento dele com uma brasileira e se consolida definitivamente quando Alberto vende o próprio filho como escravo para pagar dívidas de jogo. Kehinde sente-se culpada pela morte física do primeiro filho, Banjokô, durante o planejamento da Revolta dos Malês, e pela morte simbólica do segundo filho, deixado aos cuidados do pai e da amiga Esméria, já que, ainda conforme Silva,

O desaparecimento de Omutende [Luiz Gama], contudo, também relaciona-se à participação da sua mãe na Revolta dos Malês. O desfecho da ação rebelde instaura uma severa perseguição política aos africanos no Brasil, perseguição que, em última instância, pouco tempo depois agravada por outras revoltas, impele a narradora a sair de Salvador [...] (p. 180).

As tentativas de reencontrar o filho conduzem a narradora ao Rio de Janeiro e a São Paulo, à Nigéria e, por fim, novamente ao Brasil. Durante a viagem de retorno à África, Kehinde encontra um novo companheiro, também africano, com quem tem duas crianças gêmeas ali nascidas- ibejis como ela e sua irmã Taiwo, que não resistiu à travessia atlântica no navio negreiro. Os dois últimos filhos crescem paralelamente à prosperidade material e ao crescente prestígio da “brasileira” Kehinde na África e permitem à narradora a experiência de uma descendência próspera.

Contudo, como aponta Silva, as condições da última gestação passam longe de um final feliz. Tragédias e conflitos seguem compondo as complexas relações vivenciadas por Kehinde e não diminuem seu sentimento de culpa, daí sua renovada busca pelo segundo filho. Na longa carta que escreve a este, que é o próprio texto de Um defeito de cor, há o relato de uma busca atravessada pelas experiências pessoais da narradora, que testemunha os horrores do tráfico humano, as opressões às pessoas escravizadas, as lutas cotidianas e insurreições coletivas, os acordos que culminaram na abolição e, embora o relato de Kehinde se encerre numa temporalidade anterior, antecipa as lutas contemporâneas por reparação e justiça raciais.

Nas considerações finais da pesquisa, Fabiana Silva conecta com propriedade esse devir anunciado por 
Kehinde à realidade de mães negras que ainda vivem em condições de violência, contra si e contra seus filhos. Ao considerar a potência da narrativa literária como testemunho da história, a autora compreende também a ligação entre o romance de Ana Maria Gonçalves e textos anteriores, alguns mencionados como epígrafes de cada capítulo, do prefácio às considerações finais de seu livro: Úrsula (1889), de Maria Firmina dos Reis; Negra Efigênia, paixão do senhor branco (1966), de Anajá Caetano; Barána trilha do vento (2015), de Miriam Alves; Ponciá Vicêncio (2003), de Conceição Evaristo; Quarto de despejo: diário de uma favelada (1960), de Carolina Maria de Jesus. Trazer fragmentos dessa literatura feminina negra brasileira se insinua, para além de merecido reconhecimento, como exercício de subversão da encenação literária centrada no cânone patriarcal. Outras representações de Brasil e de povo brasileiro se inscrevem nessas narrativas e põem em discussão signos identitários que, ao longo do tempo, estruturaram o racismo como marca das relações sociais.

Ao trazer para a sua pesquisa os estudos de outras mulheres, negritadas entre as muitas referências utilizadas para fundamentar sua pesquisa, Fabiana Silva reafirma o eco contemporâneo das "vozes-mulheres", em ressonância que talvez ainda se amplifique nas vozes que virão, como ensina Evaristo:

A voz de minha filha Recolhe em si A fala e o ato. O ontem - $\mathrm{o}$ hoje $-\mathrm{o}$ agora. Na voz de minha filha Se fará ouvir a ressonância O eco da vida-liberdade. ${ }^{5}$

\section{Mírian Sumica Carneiro Reis (DD}

